NASA Technical Memorandum 100417

\title{
Aircraft Flight Flutter Testing at the NASA Ames-Dryden Flight Research Facility
}

Michael W. Kehoe

(NASA-TH-100417) AIBCRAFT FIIGET FLUTTER

IESTING AT THE NASA ALES-DBYCEE FIIGHT

EESEARCH FACILITY (MASA) $17 \mathrm{~F}$ CSCL $01 \mathrm{C}$
M $88-20301$

Unclas

0136050

May 1988

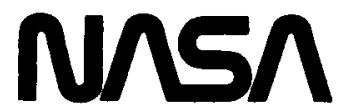

National Aeronautics and

Space Administration 
NASA Technical Memorandum 100417

\section{Aircraft Flight Flutter Testing at the NASA Ames-Dryden Flight Research Facility}

Michael W. Kehoe

Ames Research Center, Dryden Flight Research Facility, Edwards, California

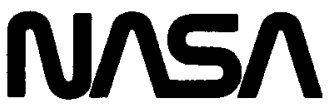

National Aeronautics and

Space Administration

Ames Research Center

Dryden Flight Research Facility

Edwards, California 93523-5000 


\author{
Michael W. Kehoe \\ NASA Ames Research Center \\ Dryden Flight Research Facility \\ Edwards, California
}

\section{Abstract}

Many parameter identification techniques have been used at the NASA Ames Research Center, Dryden Flight Research Facility at Edwards Air Force Base to determine the aeroelastic stability of new and modified research vehicles in flight. This paper presents a summary of each technique used with emphasis on fast Fourier transform methods. Experiences gained from application of these techniques to various flight test programs are discussed. Also presented are data-smoothing techniques used for test data distorted by noise. Data are presented for various aircraft to demonstrate the accuracy of each parameter identification technique discussed.

Nomencl ature

DFRF Dryden Flight Research Facility

AFTI advanced fighter technology integration

ARMA autoregressive moving average

ASE aeroservoelastic

c.g. center of gravity

CRT cathode ray tube

FEM finite element model

FFT fast Fourier transform

G structural damping coefficient

9 normal acceleration of vehicle

IFT inverse Fourier transform

KEAS knots equivalent airspeed

LE leading edge

\section{Introduction}

Modern, high-performance aircraft use thin, low-drag airfoils designed for maximum aerodynamic efficiency. This has often resulted in more flexible and flutter-prone wings. In addition, the use of high gain, digital flight control systems can result in an adverse interaction with the aircraft structural modes and cause aeroservoelastic instabilities. The desired flight envelope for new and modified research aircraft is usually verified to be free of these instabilities through flight flutter testing. To safely conduct flutter testing, proper test preparation and flutter monitoring methods are required. In addition, an accu-

* Structural dynamics group leader and member AIAA. rate and reliable parameter identification algorithm to estimate frequency and damping of critical structural modes is required to monitor the aeroelastic stability of the aircraft in flight.

Numerous parameter identification techniques are available to determine the frequency and damping from flight data.1-5 Many of these techniques estimate frequency and damping from response data for both atmospheric turbulence (unknown inputs) and forced excitation (known inputs).

Many of these techniques have been evaluated at the NASA Ames Research Center, Dryden Flight Research Facility (DFRF) to determine their suitability for analysis of flight flutter test data. Several have been successfully applied to flight test programs.6-10

The preparation necessary for flight test, flight flutter test techniques, flutter monitoring methods, and the parameter ident ification algorithms used to estimate frequency and damping are discussed in this paper. Data from several example flight test programs are presented to illustrate flight test techniques and to demonstrate the accuracy of the parameter identification algorithms used.

\section{Flight Test Preparation}

Before a safe flight research phase can be conducted, it is essential to take certain steps to predict instabilities and to conduct ground tests to correlate with these predictions. Each flight research program at the DFRF is evaluated prior to flight testing to determine which ground tests and predictive analyses are required. A balance between safety-of-flight considerations and the particular program's technical objectives is established.

To predict instabilities, a finite element model (FEM) of the entire aircraft or the portion dealing with the modification is generated to represent the structure's mass and stiffness distribution. A vibration analysis of the FEM is then conducted to determine the resonant frequency, yeneralized mass, and mode shape for each structural mode deemed potentially significant. These modal data then serve as input to aeroelastic (flutter) analyses for prediction of potential flutter mechanisms. Except for aircraft with manual, nonhydraulic flight control systems, an aeroservoelastic analysis is also performed to evaluate the stability of the interaction of the flight control system with the structural modes of the flight test vehicle.

Ground tests are then done to correlate with these predictions. Static load deflection test data can be correlated with the ylobal stiffness 
properties used in the FEM. Measured weights, c.g. locations, and inertia moments of the total vehicle and components are compared with calculated mass properties. Ground vibration tests provide measured modal data to correlate with the results of analytical vibration analyses. Open loop ground vibration tests are conducted to measure the flight control computer sensor feedback signals to correlate with the aeroservoelastic analysis predictions, and closed loop aeroservoelastic tests are used to evaluate the interaction of the flight control system with elastic structural modes. The overall structural and flight control system interactions are explored during ground resonance and limit cycle gain margin tests.11,12

Steady and unsteady aerodynamics play an important role in aeroelastic and aeroservoelastic instabilities. Wind tunnel tests of dynamically scaled flutter models are sometimes performed to confirm predicted flutter speeds. 13 Measured quasi-steady aerodynamic forces are sometimes obtained from wind tunnel tests of rigid models with instrumentation to measure total aircraft aerodynamic derivatives, pressure distributions, and control surface hinge moments.

\section{Flight Flutter Test Techniques}

The choice of flight flutter test technique is usually dictated by the presence or lack of an onboard excitation system. In general, the problem of identifying several modes of vibration to estimate damping levels is much easier and produces higher quality results with mechanical excitation systems.14 However, aircraft can be safely flutter tested by using natural atmospheric turbulence and pilot-induced control surface pulses for structural excitation.

The flight test procedure used with forced excitation is to conduct symmetric and antisymmetric sinusoidal frequency sweeps, dwells, or both at each flight condition. The sweep rate is dependent on the frequency and damping levels of the modes to be excited. Modes below $20 \mathrm{~Hz}$ have been successfully excited with sweep rates as high as $0.5 \mathrm{~Hz}$ per sec. 15 Fast logarithmic sweeps ( 4.5 decades per min) have been successfully used to excite modes in the frequency range of 10 to $40 \mathrm{~Hz} .14$

Frequency dwells are usually conducted for the critical structural modes involved in the flutter mechanism only. The duration of a frequency dwell is usually 3 to $5 \mathrm{sec}$.

Dive maneuvers are required to obtain airspeeds greater than those that can be achieved in straight and level flight. For these test points, an altitude band of approximately $\pm 1,000 \mathrm{ft}$ is created around the desired test altitude at which data are acquired, regardless of excitation type. Usually, test points that require a dive greater than $30^{\circ}$ are not attempted owing to significantly larger altitude changes in a given time period.

For a dive, the sweep rate may be changed if necessary so that the sweep is accomplished within the test altitude band. However, as the dive angle becomes steeper, the time in the altitude band becomes shorter and sweeps can no longer be conducted. At these test conditions, sinusoidal frequency dwells at the predicted critical flutter mode frequency can still be conducted to ensure that the critical mode is excited.

The majority of the flight research vehicles at the DFRF are tested using natural atmospheric turbulence. With this type of excitation, normally $60 \mathrm{sec}$ of stabilized data is obtained. On some programs, $120 \mathrm{sec}$ of data have been acquired when closely spaced modes are present. Modal density can be a problem with this type of excitation since all structural modes are excited sinultaneously. Adding and subtracting of appropriate accelerometer time history signals can assist in separating symmetric and antisymetric modes, respectively, and thereby reduce the modal density.

Natural atmospheric turbulence excitation usually requires testing at two or three different altitudes. Testing is conducted in an airspeed build-up approach at the highest altitude in order to start the testing at the lowest dynamic pressure. Generally, there is little or no structural excitation at these higher altitudes due to the lack of turbulence. This results in poor signal-to-noise ratios and makes data analysis difficult. In addition, at each test point all of the structural modes may not be adequately excited to estimate damping, resulting in holes in the damping trend information. At lower altitudes, turbulence is more readily found, and the lack of adequate excitation becomes less of a problem. At the lower altitudes, the potentially critical areas of the flight envelope are cleared.

Test points that require dives can be accomplished by acquiring random structural responses caused by natural atmospheric turbulence. One or more averages of data can be acquired in the test band, depending on dive angle and airspeed of the test vehicle. The dive maneuver can be repeated until the desired number of averages is obtained to provide a good statistical sample of data at this test condition.

For large transport type aircraft, control surface pulses have worked well owing to typically lower primary modal frequencies. A control surface pulse can typically excite modes up to a frequency of $5 \mathrm{~Hz}$. Since the majority of elastic modes of interest for the primary surfaces are less than $5 \mathrm{~Hz}$ for transport type aircraft, this type of excitation is suitable. Pulses are usually done in both directions and for all three axes.

For test points that require dives, the aircraft is pulsed in only one direction in the pitch, roll, and yaw axes in the desired test altitude band. These pulses can usually be accomplished in the test altitude band even for steep dives.

The effects of stability augmentation systems and autopilots on the vehicle's aeroelastic stability are checked periodically during the flutter envelope expansion. In addition, the effect of 
angle of attack on structural damping is also monitored by performing turns at normal acceleration levels above $1 \mathrm{~g}$. Typically, these data are acquired for every other test point.

A real-time guidance system was developed to aid the pilot in maintaining the flight test conditions.16 With this system the pilot flies the airplane to minimize the computed differences between the desired and actual flight state condition (altitude and Mach number). The computed differences are telemetered to the airplane from a ground-based computer. The pilot then uses a cockpit display as an aid to acquire and hold desired test conditions. This approach has been found to be a very effective way to obtain exceptionally accurate stabilized flight test conditions.

\section{Flutter Monitoring}

The aeroelastic stability of the vehicle is continuously monitored during flight flutter testing in a dedicated ground station facility. Accelerometers, strain gages, or both are mounted on the test vehicle to measure structural response. These transducer outputs are telemetered to the ground station and displayed on strip charts. The traces are observed for sinusoidal motion and unusual modal activity throughout the test. For onboard excitation, such as frequency sweeps, dwells, and control surface pulses, the rate of decay for the modes excited is also monitored.

Real-time frequency spectral analysis displays are used to monitor the change in modal energy for important modes during the flight, particularly when the vehicle is being accelerated to the next higher airspeed. Often, the modes that are involved in a critical flutter mechanism, such as wing bending and torsion, are monitored on these displays simultaneously to observe frequency coalescence trends.

Software is implemented on a minicomputer to estimate frequency and damping of critical structural modes during the flight test. After data acquisition of usually 4 to 10 channels of accelerometer outputs, approximately $30 \mathrm{sec}$ per data channel is currently required for data analysis and a hard copy of results. The two channels of data, which are determined to be the ones with the most modal information, are typically analyzed during the flight test to estimate the frequency and damping of the structural modes. These values are then plotted as a function of airspeed. Clearance to the next higher airspeed point is given by the flutter test director after the damping coefficients and trends for the structural modes are determined to be satisfactory.

Additional, comprehensive postflight data andlysis is performed between flights. This analysis usually consists of analyzing the remaining data channels and establishing frequency and damping trends for structural modes that are considered not to be critical.

\section{Flutter Parameter Identification Methods}

Many parameter identification methods have been evaluated at the DFRF to determine their suitability for analysis of flight flutter test data. The ones that have been used most successfully are the fast Fourier transform, time lay products, and recursive identification algorithms.

\section{Fast Fourier Transform Methods}

The fast Fourier transform method is the primary technique used at the DFRF to clear an aeroelastic and aeroservoelastic flight envelope in near-real time. This method can be used for both turbulence and onboard mechanical excited responses.

The random-data power spectrum analysis consists of calculating the power spectrum for each average of random data. A flow chart is shown in Fig. 1. Random data are typically acquired using a data block size of 1024 samples and a sampling rate of 100 samples per sec $(10.24 \mathrm{sec}$ of data per average). The frequency content of this data is obtained by performing the fast Fourier transform (FFT). This complex frequency function is then multiplied by its complex conjugate to obtain a power spectrum. The procedure is repeated and the power spectra are averaged until all of the time history data are used; Fig. 2 is an example of the final averaged power spectrum. Note that for this example one larger mode of vibration exists with two smaller or secondary modes. At this time the flutter engineer selects the primary mode of interest and decides which modes will be zeroed out in the frequency domain using a boxcar window to produce a single degree of freedom spectrum. By performing an inverse Fourier transform (IFT) of the single degree of freedom power spectrum, a circular autocorrelation function (Fig. 3) is obtained. This autocorrelation is a comparison of the signal with itself as a function of a time shift and is mathematically symmetric within the block. At this time, zeros are inserted to smooth the data. The zeros remove the right portion of the autocorrelation function and remove the noise tails. Figure 4 shows the autocorrelation function after the zeros have been inserted. The autocorrelation function is multiplied by an exponential window to smooth the transition to the zero values. This window is equal to unity at zero sec and has a value of 0.02 at the cutoff time selected by the operator. The resulting autocorrelation function is shown in $\mathrm{Fig} .5$. A Fourier transform of this autocorrelation function gave the smoothed power spectrum shown in Fig. 6.

A least-squared error parabolic curve is then $f i t$ to the peak. The modal frequency is defined as the frequency at the peak, and the structural damping is determined from the half-power frequencies, that is, structural damping is the upper half-power frequency minus the lower halfpower frequency, all divided by the modal frequency. The output of modal information is printed on Fig. 6. This information consists of the following:

\section{Modal frequency,}

2. Total damping which is a sum of the exponential smoothing function damping and the modal damping (total damping $(G)$ ), 
3. Modal damping which is the damping value obtained after the exponential smoothing function damping was subtracted (damping (G)), and

4. Number of the power spectrum data points used in the least-squared error curve fit (number of points in fit).

A frequency response function is calculated when a measurement of the excitation force is available. The data may be acquired into one data block or may be averaged into one data block by either time or frequency averaging. Time averaging has been shown to be better for sine sweeps.17 The data block size and sampling rate are selected to acquire the data within the time required for the sweep. Once the frequency response function is calculated, frequency and damping can be estimated using the same procedure as for the random data power spectrum analysis.

An alternate analysis method is available for determining the frequency and damping from frequency response functions. Near each resonant response, a near circle is traced out in the Argand plane (Fig. 7). The point on the plot where the greatest change in arc length per unit of frequency occurs is the natural frequency. The damping of each mode is determined from the frequency rate of change al ong the resonance curve. 18 A least-squared error circle fit is performed to determine the frequency and damping.

The accuracy of the damping estimate is critically dependent on the selection of the zero insertion and exponential cutoff times. This is an important point concerning the use of this algorithm. The analyst must decide how many seconds of the signature are truly representative of the structure. Therefore, the analyst must know as much about the aircraft modal characteristics as possible prior to flight testing in order to make intelligent decisions concerning exponential cutoff times and their effects on the resulting estimates.

Autocorrelation functions of simulated data were used to study the effects of varying the zero insertion and exponential cutoff times on the estimation of damping. Shown in Figs. 8 and 9 are autocorrelation functions of simulated data with a signal-to-noise ratio of infinity and a signalto-noise ratio of 10 , respectively. Typical flight test data obtained from atmospheric turbulence excitation has a signal-to-noise ratio of about 10. Signal-to-noise ratios are generally higher with mechanical excitation. The mode in Fig. 8 has a frequency of $8.0 \mathrm{~Hz}$ and a structural damping of 0.099 , whereas the mode in Fig. 9 has a frequency of $7.83 \mathrm{~Hz}$ and a structural damping of 0.090 .

Shown in Figs. 10 and 11 are the damping estimates which resulted by varying the zero insertion time from 5.12 to $0.62 \mathrm{sec}$ while maintaining the exponential cutoff time constant at $7.5 \mathrm{sec}$ for the autocorrelation functions shown in Figs. 8 and 9. As indicated in both figures, the damping estimate increased in value only when the inserted zeros eliminated data points from the autocorrelation function that truly repre- sented the response of the structure. It is al so interesting to note, that with an infinite signalto-noise ratio, very little smoothing is required to obtain an accurate estimate of damping while the autocorrelation function with a signal-tonoise ratio of 10 yielded a less accurate estimate of damping with the same smoothing.

The effects of varying the exponential winNow cutoff time are al so shown in Figs. 10 and 11. The damping values were obtained by maintaining the zero insertion time constant at $1.5 \mathrm{sec}$ and then varying the exponential cutoff time from 5.12 to $0.62 \mathrm{sec}$ for the autocorrelation functions shown in Figs. 8 and 9. Multiplication of the infinite signal-to-noise ratio autocorrelation function (Fig. 8) with an exponential window indicated degradation in accuracy of the damping estimate as the cutoff time was decreased. For the autocorrelation function with a signal-to-noise ratio of 10 (Fig. 9), the exponential window initially improved the damping estimate, but further decreases in the cutoff time below $3 \mathrm{sec}$ degraded the damping estimates.

\section{Recursive Identification Algorithm}

An algorithm to estimate frequency and damping using a recursive identification technique 19 with forced and natural turbulence excitation is used during postflight analysis of data. Recursive identification refers to algorithms that update est imates at every sampling instant. Autoregressive moving average (ARMA) models are used in the algorithm. The ARMA model can be overparameterized to automatically account for colored sensor noise. A signal-to-noise ratio of approximately 10 or greater yields accurate frequency and damping estimates for forced and natural turbulence excitation.

The program setup parameters are entered interactively and consist of the following:

1. Specifying whether or not the input is known,

2. Specifying the number of data points to be analyzed,

3. Specifying the number of modes to be modeled (maximum of six), and

4. Specifying how often the frequency and damping estimates are printed.

This algorithm has been used with some success and appears to be a promising approach to estimate frequency and damping. Research is continuing on improving the performance of this algorithm.

Time Lag Products

The time lag products method 20 is used for postflight analysis only because of the computer time requirements. The data are acquired from digitized time histories of high-samplerate accelerometer outputs. The data are passed through a digital bandpass filter with the center frequency and bandwidth specified by the user. 
The autocorrelation (random turbulence excitation) or impulse response (forced excitation) function is calculated from the filtered time response data and then transformed into the frequency domain by the direct Fourier transform. Smoothing with an exponential window can be done before the transformation is performed. The modal frequency and damping are then determined in the same manner as for the FFT method.

\section{Example flight Test Programs}

\section{F-16 Decoupler Pylon Program}

The decoupler pylon program was a concept of passive wing-store flutter suppression achieved by providing a low-store-pylon pitch frequency. 6 The decoupler pylon dynamically isolates the wing from the store pitch inertia effects by providing a lowstore pitch frequency. The store was allowed to rotate in pitch, but its motion was restrained by a soft spring and damper.

Flight tests were performed on an F-16 airplane carrying an AIM-9J missile, a GBU-8 store, and a 370-gal external fuel tank on each wing (Fig. 12). Flight of the airplane with the GBU-8 mounted on a standard production pylon is characterized by a limited amplitude flutter. The airplane, when flown with the GBU-8 mounted on a decoupler pylon, successfully suppressed this wing-store flutter throughout the flight envelope.

This program used an onboard excitation system, consisting of the wing flaperons and natural atmospheric turbulence for excitation. The wing flaperons were commanded to provide sinusoidal frequency sweeps and dwells. The frequency range of the sweep was from 2 to $20 \mathrm{~Hz}$ and the sweep rate was $0.6 \mathrm{~Hz}$ per sec. The frequency dwells were set for $3 \mathrm{sec}$ in duration. Antisymmetric sweeps and dwells and $60 \mathrm{sec}$ of random response to atmospheric turbulence were collected at each test condition.

The frequency sweep data were found not to be useful for estimation of frequency and damping. The sweep rate was too fast for this heavy store loading and the location of the flaperons on the inboard portion of the wing could not adequately excite all of the modes of interest. In this case, the sweep rate could not easily be changed on the airplane to try to improve the excitation of the modes of interest.

The frequency dwells ( $3 \mathrm{sec}$ in duration) were used primarily to excite the GBU-8 pitch mode. Using the flaperons to accomplish this worked exceptionally well. For the other modes, frequency and damping values were estimated from the response data excited by random atmospheric turbulence.

Baseline flights with the GBU-8 mounted on a standard production pylon established that this configuration is characterized by an antisymmetric limited amplitude flutter oscillation within the operational flight envelope. These baseline flights with the standard pylon provided a unique opportunity to validate the FFT algorithm since this configuration was previously determined to experience a limited amplitude flutter oscillation at 0.7 Mach number. The damping trend shown in Fig. 13 was obtained by a least-squared error $f i t$ to the data. Extrapolation of this data trend from 0.6 Mach number to zero damping provided an instability airspeed prediction which agreed closely with the actual instability onset airspeed encountered.

\section{KC-135 Winglet Program}

A flight test program was conducted on a $\mathrm{KC}$ 135 airplane (Fig. 14) to demonstrate and validate the potential aircraft performance gains due to winglets. Winglets are small, nearly vertical aerodynamic surfaces designed to be mounted at the tips of aircraft wings. These flight test winglets were designed so that the winglet cant and incidence angles could be changed between flights. 7

Flight flutter testing of the airplane was required due to the addition of the winglets and associated structural modifications to the wing. The airplane was excited with pilot-induced control surface pulses. The FFT algorithm was used to acquire the structural response from each pulse and to estimate frequency and damping.

Flight test results indicated that a lightly damped oscillation occurred for a winglet configuration of $0^{\circ}$ cant and $-4^{\circ}$ incidence angles. The subcritical damping trend for a 2.6 and a 3.0-Hz mode are shown in Fig. 15. The data exhibited a constant increase in frequency for the 2.6-Hz mode while the $3.0-\mathrm{Hz}$ mode frequency trend remained flat. It appeared that the coalescence of these two modes was the cause of the oscillation. The damping trends for both modes exhibit a constant decrease in damping starting at 330 knots equivalent airspeed (KEAS). The modes could no longer be separated at airspeeds above 356 KEAS. Time histories of several accelerometers at the last test point are shown in Fig. 16. This example illustrates the accuracy of the FFT algorithm using control surface pulses for structural excitation.

Schweizer 1-36 Deep-Stall Sailplane

A Schweizer 1-36 sailplane (Fig. 17) was modified to conduct aircraft controllability research in the deep-stall region above an angle of attack of $30^{\circ}$. The sailplane was a single place, allaluminum construction, except for the rudder which was covered by fabric. The horizontal stabilizer was a T-tail configuration, and it was modified so that it could pivot as much as $70^{\circ}$ leading edge down. This structural modification made it necessary to conduct a flutter clearance program.

A unique approach was taken on this program to investigate the flutter characteristics prior to flight testing. The instrumented fuselage and tail were mounted to the bed of a truck (Figs. 18 and 19) and tested by driving the truck across a dry lakebed at high speed into prevailing winds. In this manner, the actual intended maximum airspeed of 90 knots (60-knot groundspeed and 30-knot headwind) was safely obtained on the ground. This approach was taken because the nonlinear structural dynamic characteristics of the pivoting tail 
precluded a conventional flutter analysis. Upon completion of the ground test, a flight flutter test $^{9}$ was conducted.

Since the sailplane was in a continuous descent during flight, the vehicle was stabilized at a constant airspeed, and data was acquired in altitude bands of $\pm 1,000 \mathrm{ft}$ about the desired test altitude. Natural atmospheric turbulence was used as excitation, and typically $20 \mathrm{sec}$ of data was acquired at each test point since the amount of flight time was limited on each flight.

The sailplane was cleared in real time by monitoring accelerometer time history traces on a strip chart. It was felt that this method of clearing the envelope was safe based on the ground flutter (truck-mounted) test results.

Postflight analysis consisted of estimating the frequency and damping using the time-lag products algorithm. Frequency and damping trends of several modes were established from this limited amount of data with very little scatter in the damping estimates. Figures 20 and 21 show typical frequency and damping results and the agreement between flight and ground test data.

\section{AFTI/F-16 Aeroservoelastic and Flutter Program}

An F-16 aircraft was modified to become a testbed aircraft for the advanced fighter technology integration (AFTI) program (Fig. 22). Modifications to the airplane included installing a digital flight control system and adding canards under the engine inlet duct. Aeroservoelastic (ASE) and flutter testing were conducted 10 to clear a sufficient flight envelope for performance, stability and control, and loads testing.

The FFT algorithm was used to establish the frequency and damping trends for every mode with the exception of the symmetric missile pitch and ant isymmetric wing-bending modes. These modes were heavily damped and closely spaced. An analysis using the FFT algorithm resulted in smearing these modes together (Fig. 23). The recursive identification algorithm was used and could separately identify both modes and estimate their respective frequency and damping. An example of the convergence of the algorithm on a damping value is shown in Fig. 24. It was found that by resampling the 400 samples per sec response data at 25 samples per sec (with appropriate antialiasing filters), not only were the higher frequency modes removed but also the amount of scatter in the estimated values was reduced.

Flight flutter and ASE flight testing were successfully accomplished on the AFTI/F-16 airplane. The frequency and damping trends for all modes of interest were established by using the FFT and recursive identification algorithms.

\section{Conclusions}

Flight flutter testing is conducted to verify that a desired flight envelope is free of aeroelastic and aeroservoelastic instabilities. The hardware and software used at the DFRF during flutter testing have given the test engineer useful tools for doing modal analys is in near real time. A variety of parameter estimation techniques needs to be available for the estimation of frequency and damping for various types of excitation and for analyzing noisy data. No one technique works best for all situations. Most techniques work well when the signal-to-noise ratio of the data is high, but tend to give less accurate results when they are applied to data which have been contaminated by noise. All techniques are limited to some extent with respect to the number of modes that can be tracked in a realtime environment. Several techniques have been presented in this paper that have worked well at the DFRF in near real time. To use these algorithms, an experienced flutter engineer is essential to the process of correctly analyzing data and determining whether it is safe to proceed to the next flutter test point.

\section{References}

1Wendler, B.H.: Near-Real-Time Flutter Boundary Prediction From Turbulence Excited Response. AIAA-83-0814, May 1983.

2Roy, Richard; and Walker, Robert: Real-Time Flutter Identification. NASA CR-3933, 1985.

3Cole, H.A., Jr.: On-Line Failure Detection and Damping Measurement of Aerospace Structures by Random Decrement Signatures. NASA CR-2205, 1973.

${ }^{4}$ Houbolt, J.C.: Subcritical Flutter Testing and System Identification. NASA CR-132480, 1974.

5Flutter Testing Techniques. Proceedings from conference held at Dryden Flight Research Facility, Edwards, California, October 1975. NASA SP-415, 1976.

${ }^{6}$ Cazier, F.W., and Kehoe, M.W.: Flight Test of a Decoupler Pylon for Wing/Store Flutter Suppression. AIAA-86-9730, April 1986.

$7 \mathrm{KC}-135$ Winglet Program Review. Proceedings from symposium held at Dryden Flight Research Facility, Edwards, California, September 1981. NASA CP-2211, 1982.

8kehoe, M.W.: KC-135A Winglet Flight Flutter Test Program. Air Force Flight Test Center, Edwards Air Force Base, California, AFFTC TR-81-4, June 1981.

${ }^{9}$ Kehoe, M.W.; and Ellison, J.F.: Flutter Clearance of the Schweizer 1-36 Deep-Stall Sailplane. NASA TM-85917, 1985.

10Kehoe, M.W.: AFTI/F-16 Aeroservoelastic and Flutter Flight Test Program - Phase I. NASA TM-86027, 1985.

11Pel oubet, R.P., Jr.; Haller, R.L.; McComb, C.N.; and Bolding, R.M.: Ground Vibration Testing of Fighter Aircraft With Active Control Systems. Air Force Flight Dynamics Laboratory, 
Wright-Patterson Air Force Base, AFFOL-TR-76-110, December 1976.

12Flynn, J.; Martone, E.; and Anderson, P.: Results of the Ground Vibration Survey (GVS)/ Integrated Flight Control System (FCS) Tests of the $X-29$ Aircraft. 712/ENG-RPT-85-006, Grumman Aerospace Corporation, Calverton, New York, July 1985 .

13Reed, W.H., III: Aeroelasticity Matters: Some Reflections on Two Decades of Testing in the NASA Langley Transonic Dynamics Tunnel. NASA TM-83210, 1981.

14Gilyard, G.B; and Edwards, J.W.: Real-Time Flutter Analysis of an Active Flutter-Suppression System on a Remotely Piloted Research Aircraft. AGARD-CP-339, February 1983.

15kehoe, M.W.: F-15A/B Nestable Fuel Tank Ground Vibration, Flight Flutter and Loads Demonstration
Test Program. Air Force Flight Test Center, Edwards Air Force Base, California, AFFTC TR-79-14, May 1979.

16Meyer, R.R., Jr.; and Schneider, E.T.: RealTime Pilot Guidance System for Improved Flight Test Maneuvers. AIAA-83-2747, November 1983.

17Lenz, R.W.; and Foreman, D.A.: Digital Time Series Analysis of Flutter Test Data. AGARD-R-646, April 1976.

18Broadbent, E.G.: Vector Plotting as an Indication of the Approach to Flutter. NASA SP-385, 1958.

19walker, Robert; and Gupta, Naren: Real-Time Flutter Analysis. NASA CR-170412, 1984.

200obbs, S.K.; and Hodson, C.H.: Determination of Subcritical Frequency and Damping From B-1 Flight Flutter Test Data. NASA CR-3152, 1979. 


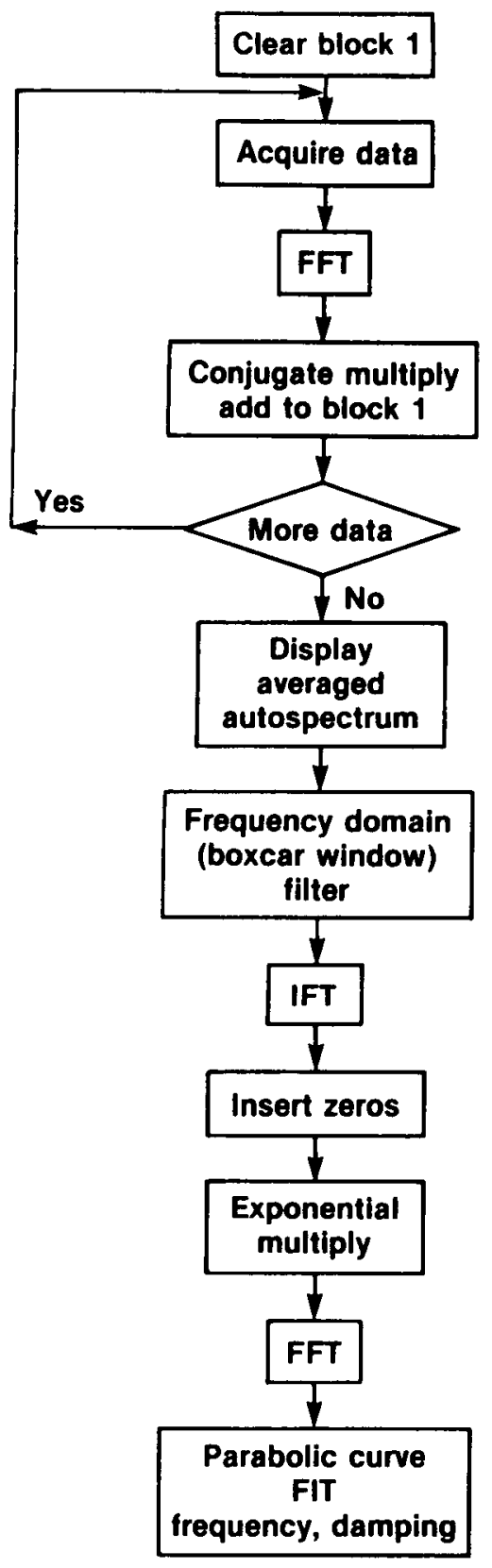

Figure 2

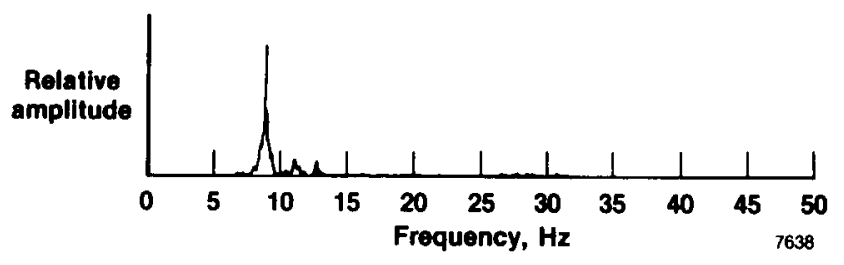

Fig. 2. Averaged power spectrum.

Figure 3

Figure 4

Figure 5

Fig. 1. Flow chart of the fast Fourier transform method.

8 


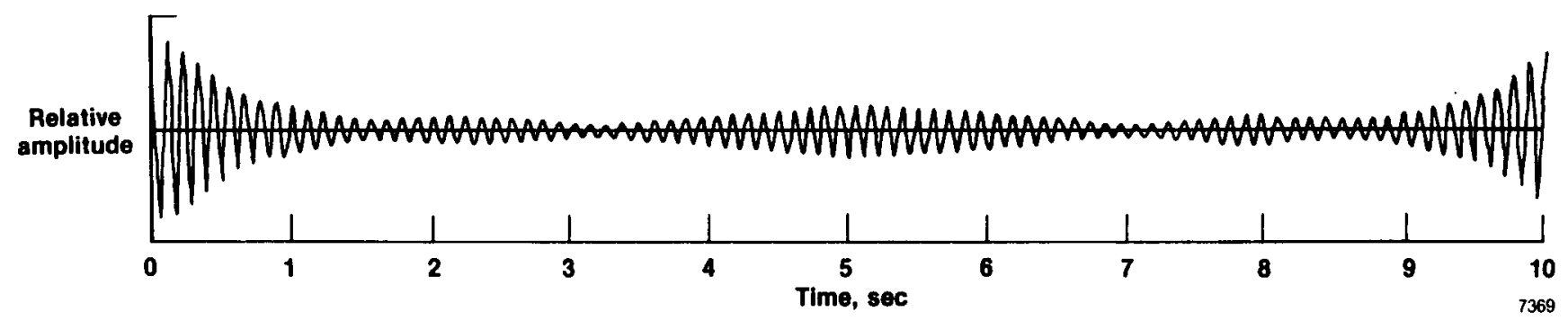

Fig. 3. Circular autocorrelation function.

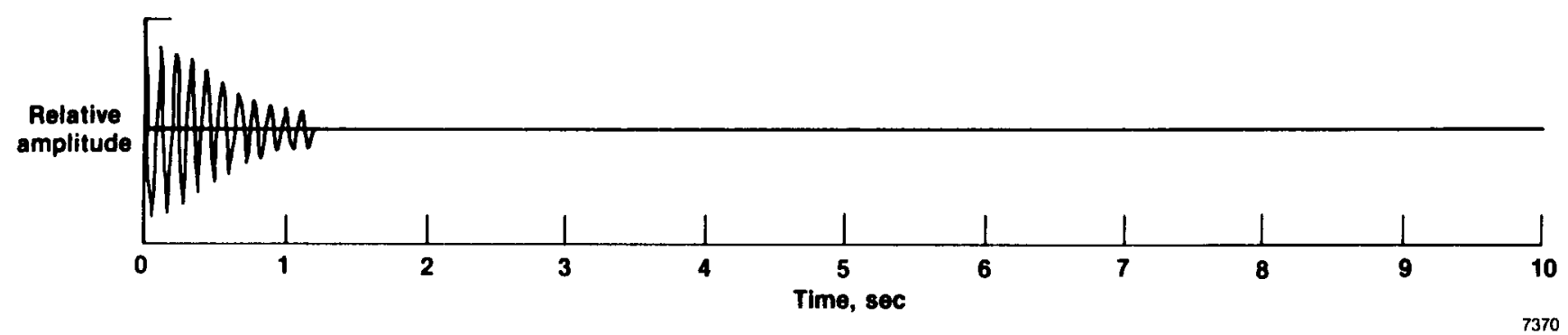

Pig. 4. Autooorrelation function with seros inserted.

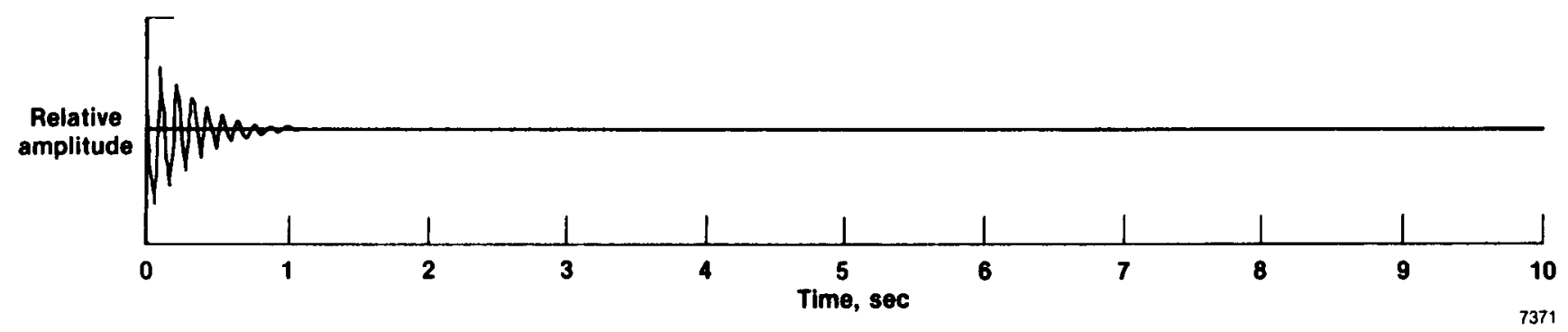

Fig. 5. Autocorrelation function multiplied by an exponential function.

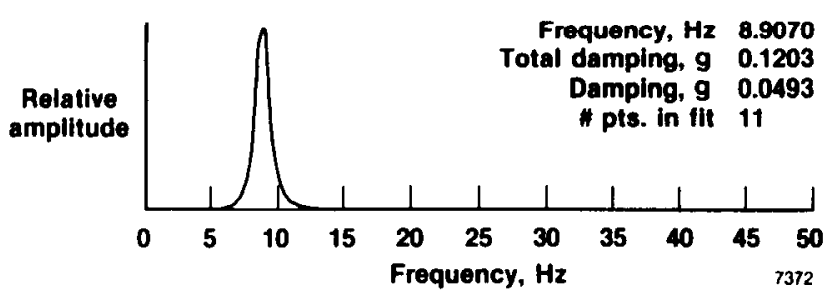

Fig. 6. Smoothed power spectrun.

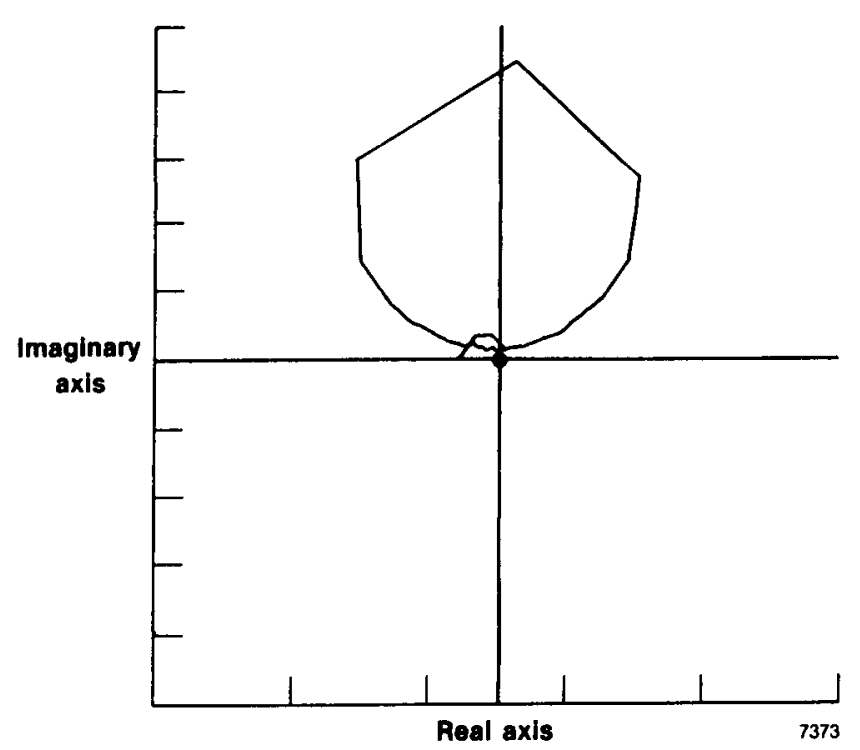

Fig. 7. Argand plot of a frequency response function. 


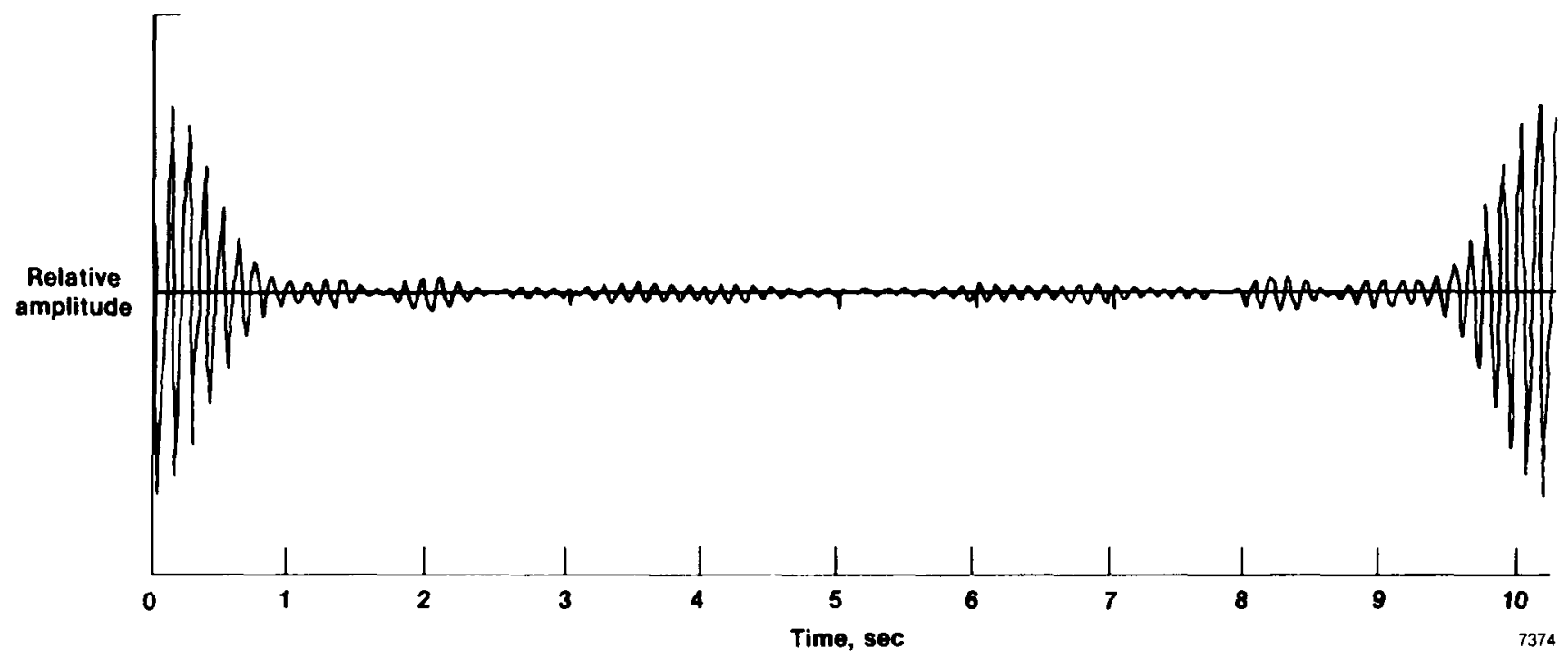

Fig. 8. Autocorrelation function of an 8.0-Hz mode with 0.099 structural damping with an infinite signalto-noise ratio.

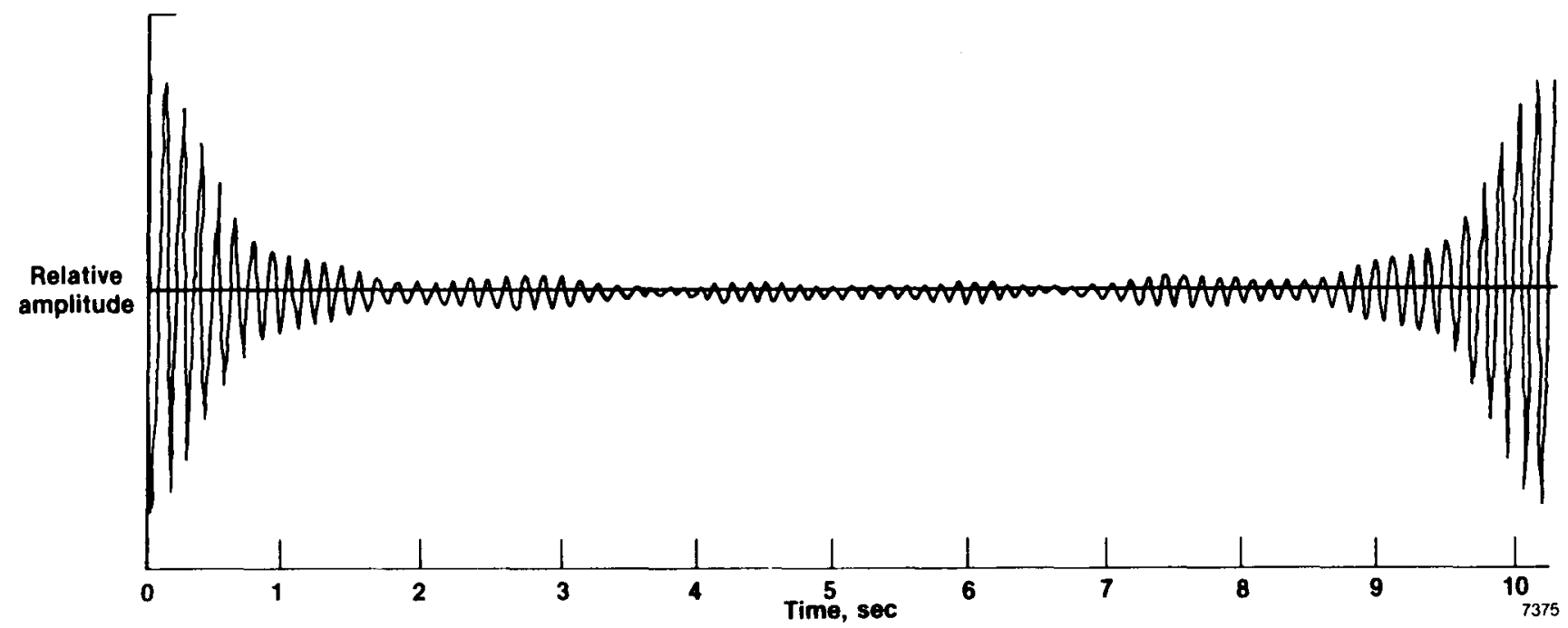

Fig. 9. Autocorrelation function of a $7.83 \mathrm{~Hz}$ mode with 0.09 structural damping with a signal-to-noise ratio of 10 . 
O Exponential time constant at 7.5 sec, zero insertion time varying

$\square$ Zero insertion time constant at $1.5 \mathrm{sec}$, exponential time varying

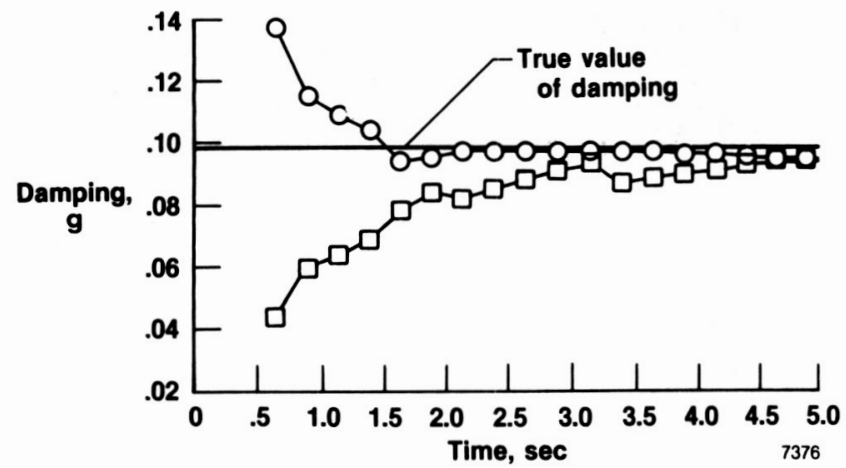

Fig. 10. Damping estimates obtained by varying the sero insertion and exponential times for an 8.0-Hs mode with a signal-to-noise ratio of infinity.
O Exponential time constant at $7.5 \mathrm{sec}$, zero insertion time varying

$\square$ Zero insertion time constant at $1.5 \mathrm{sec}$ exponential time varying

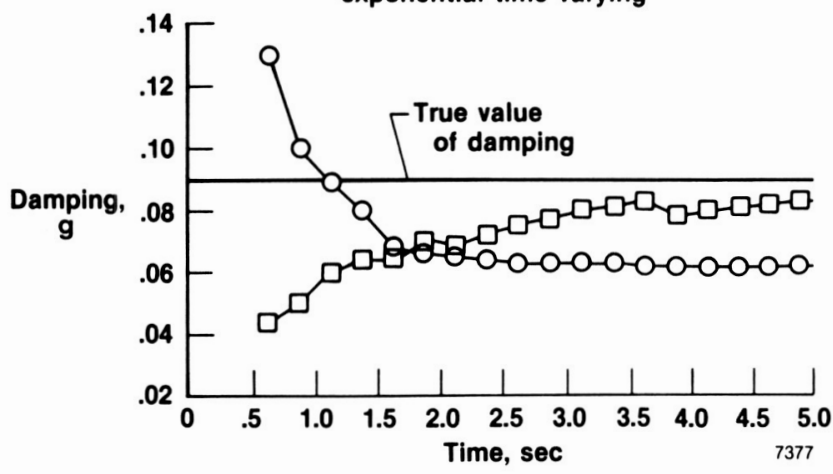

Fig. 11. Damping estimates obtained by varying the sero insertion and exponential times for a 7.83-Hz mode with a signal-to-noise ratio of 10 .

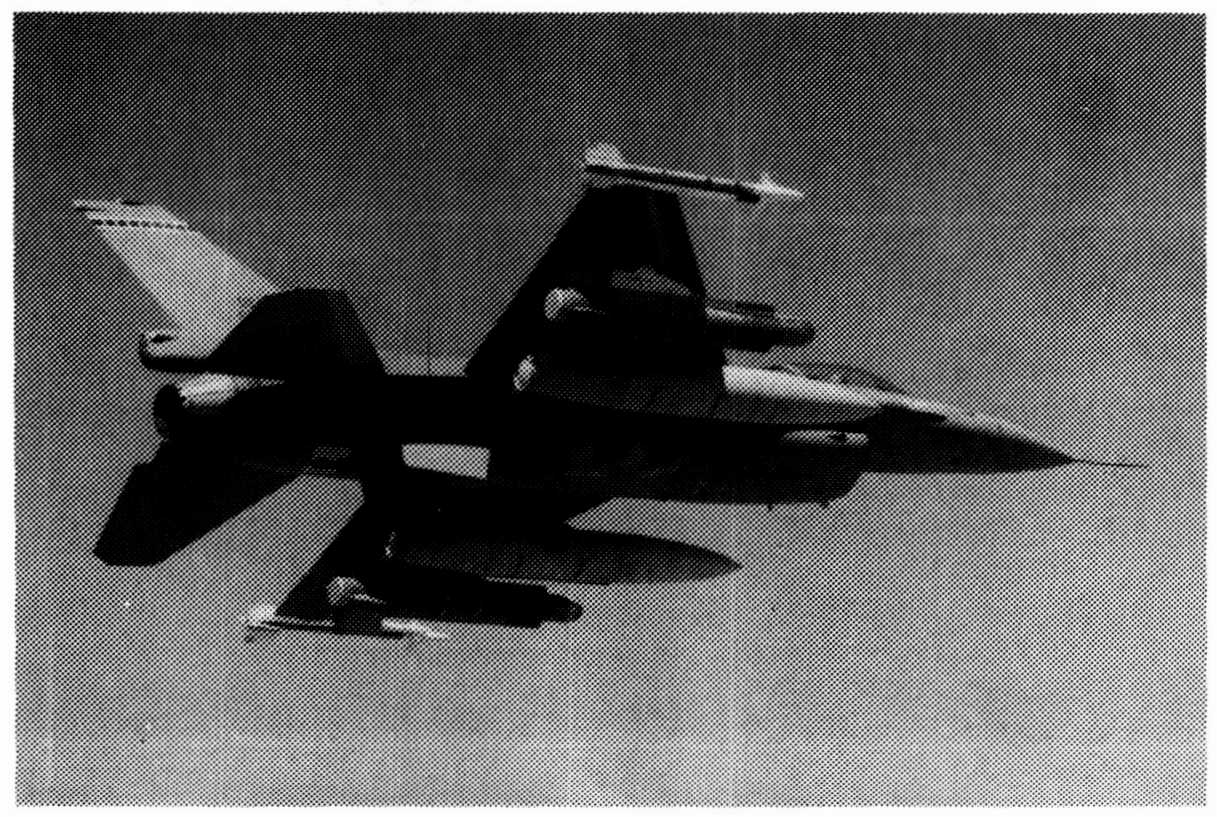

Fig. 12. F-16 airplane configured with stores.

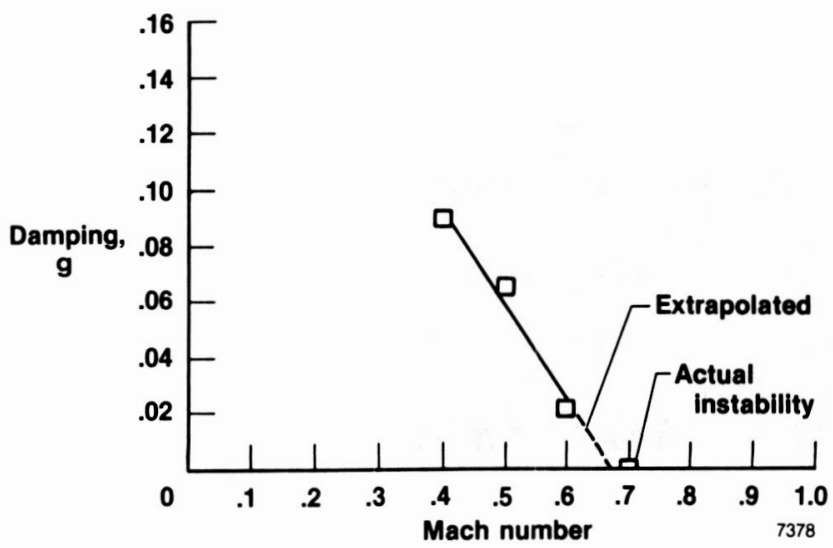

Fig. 13. Damping trend for a limited amplitude instability. 


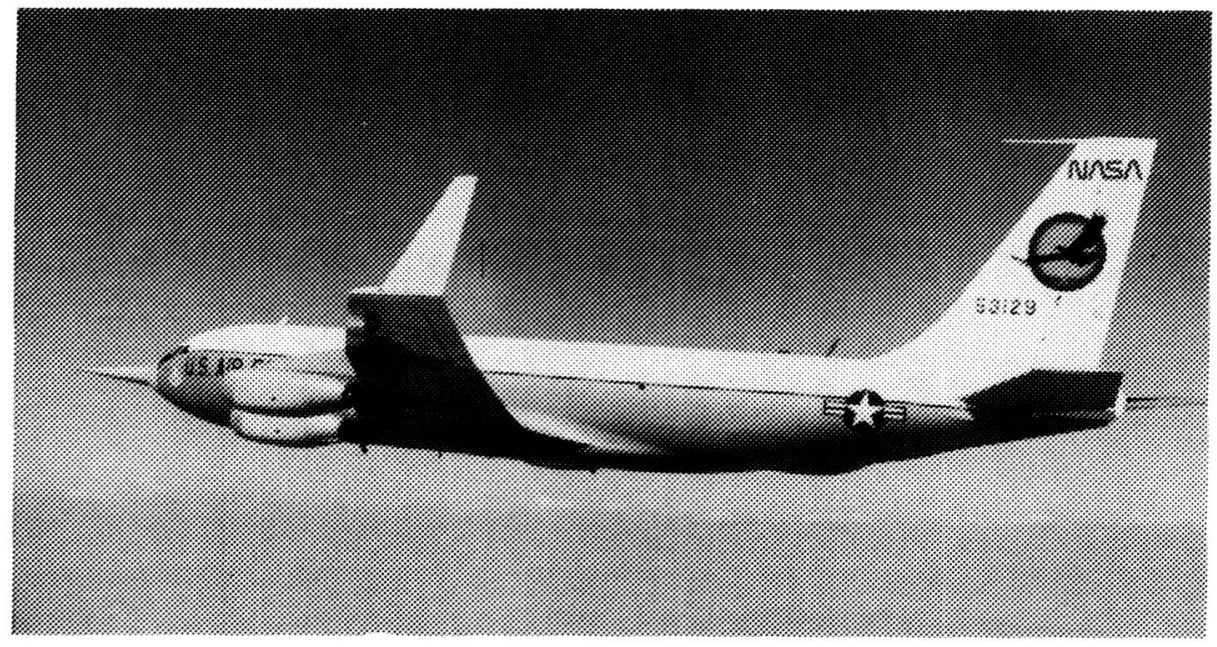

Fig. 14. KC-135 airplane configured with wrnglets.
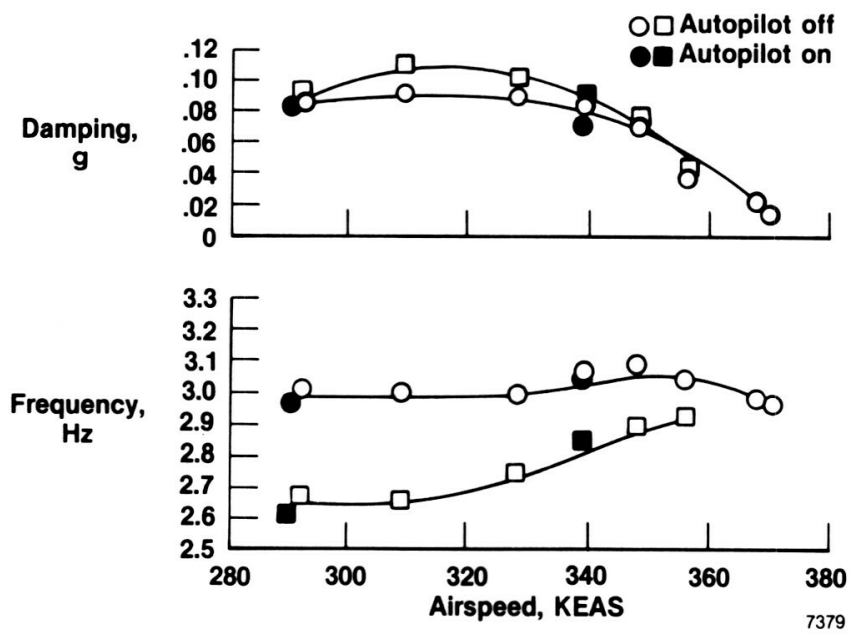

Fig. 15. Frequency and damping trends established from flight data.
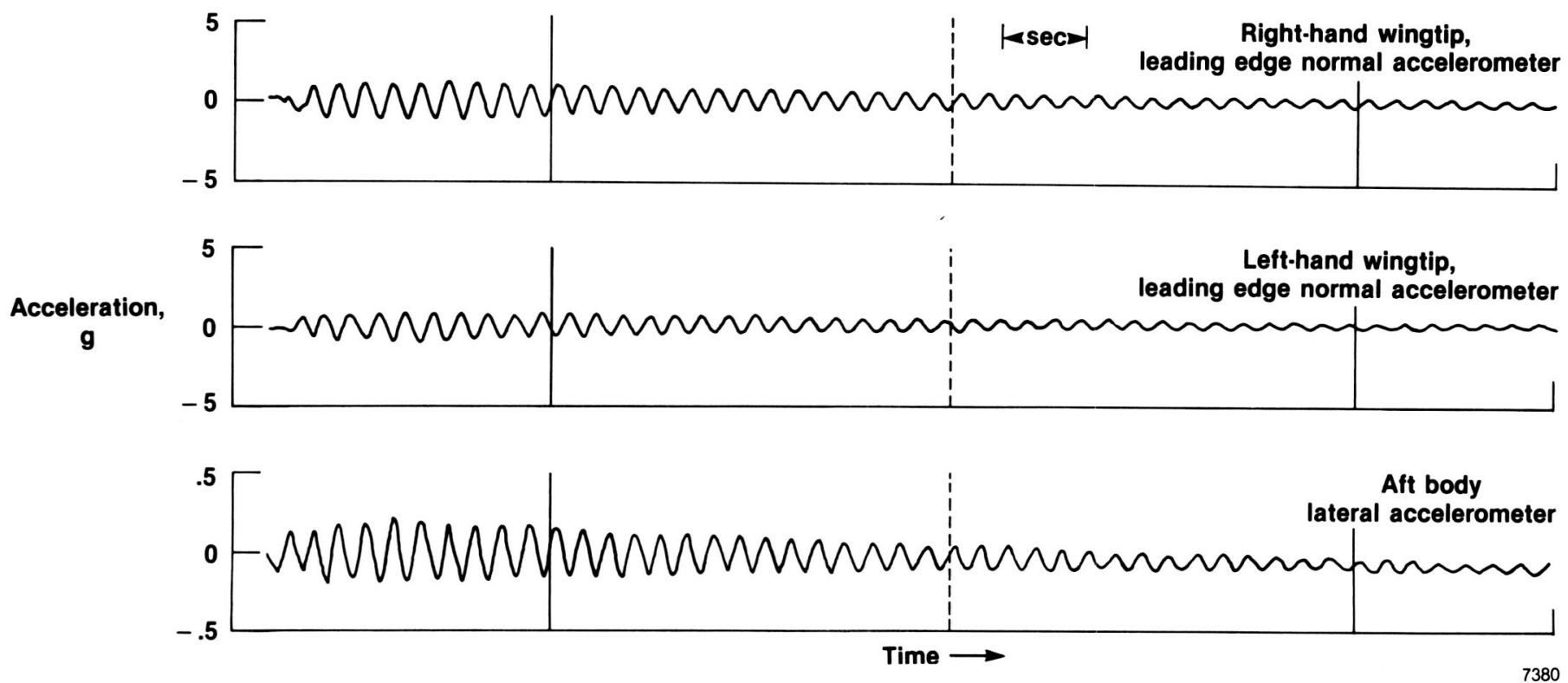

Fig. 16. Time history of a $3.0 \mathrm{~Hz}$ antisymmetric oscillation. 


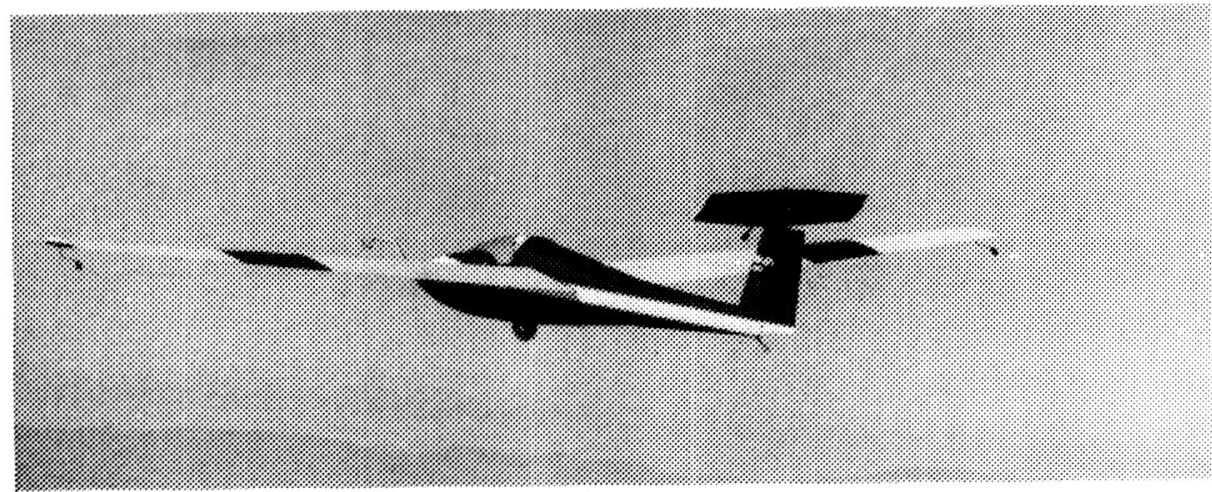

Fig. 17. Schweizer 1-36 deep-stall sailplane.

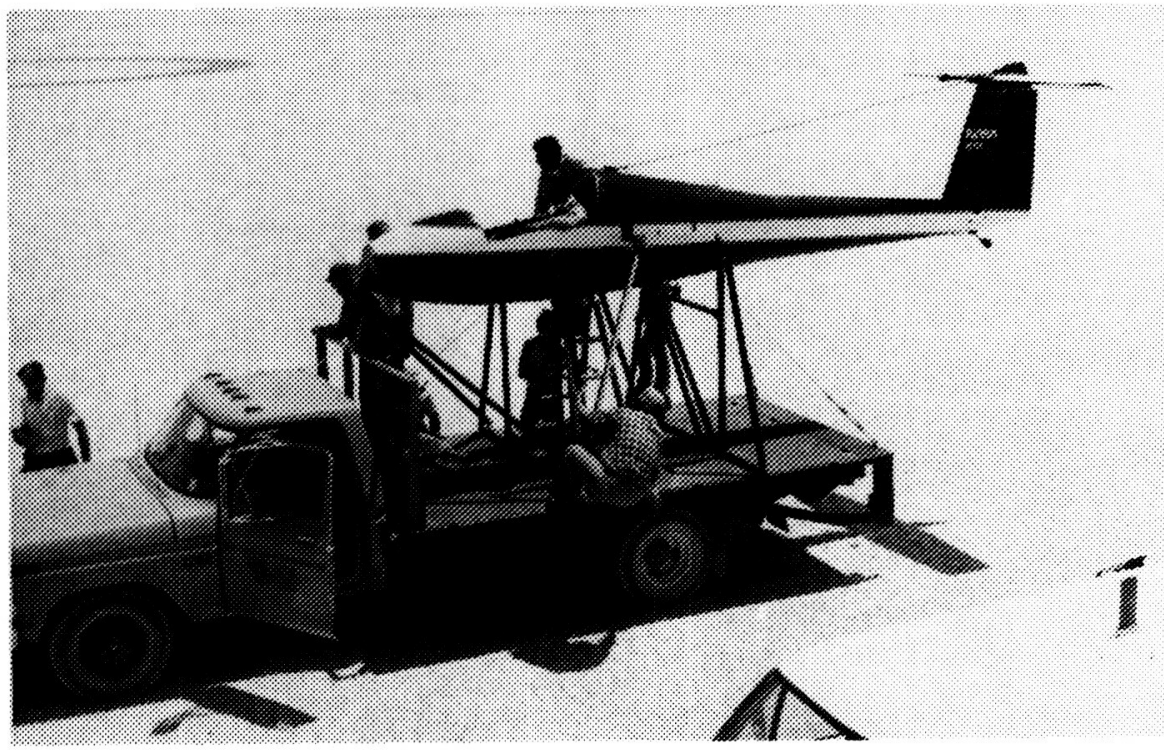

Fig. 18. Truck-mounted sailplane with the horizontal stabilizer in the normal position.

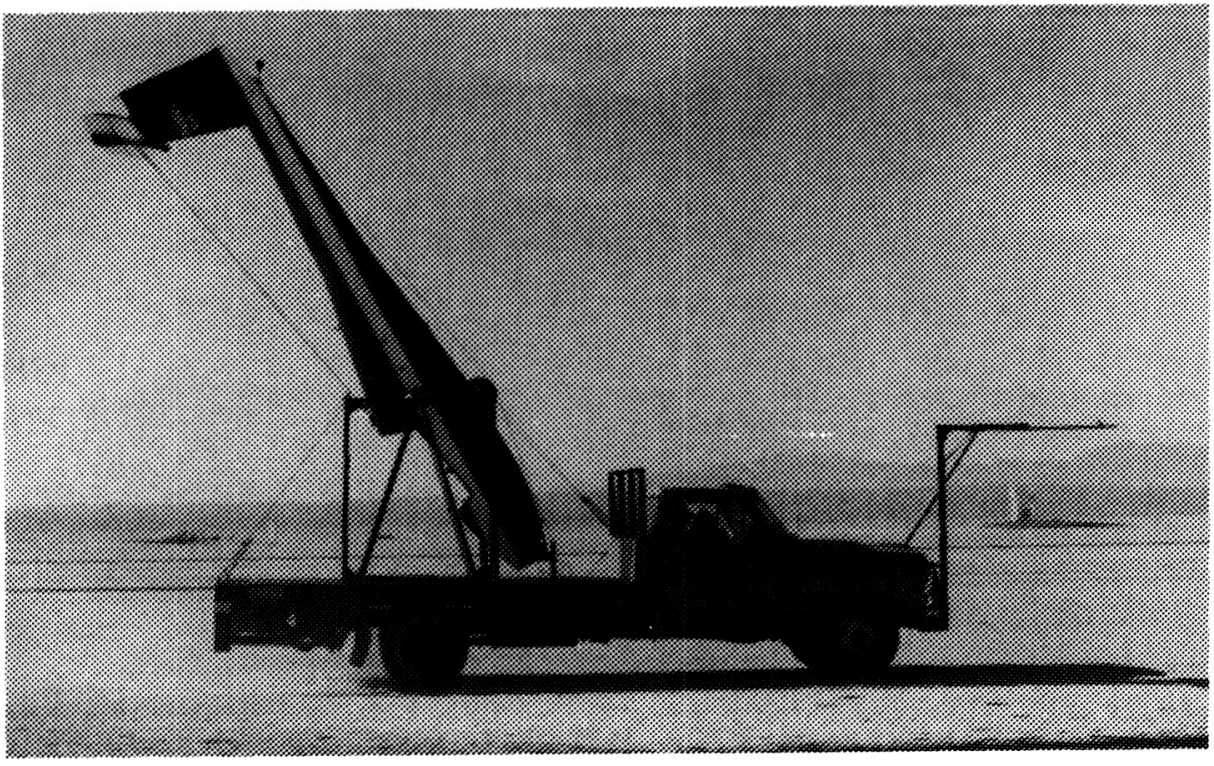

Fig. 19 Truck-mounted sailplane with the horizontal stabilizer in the deepstall position. 

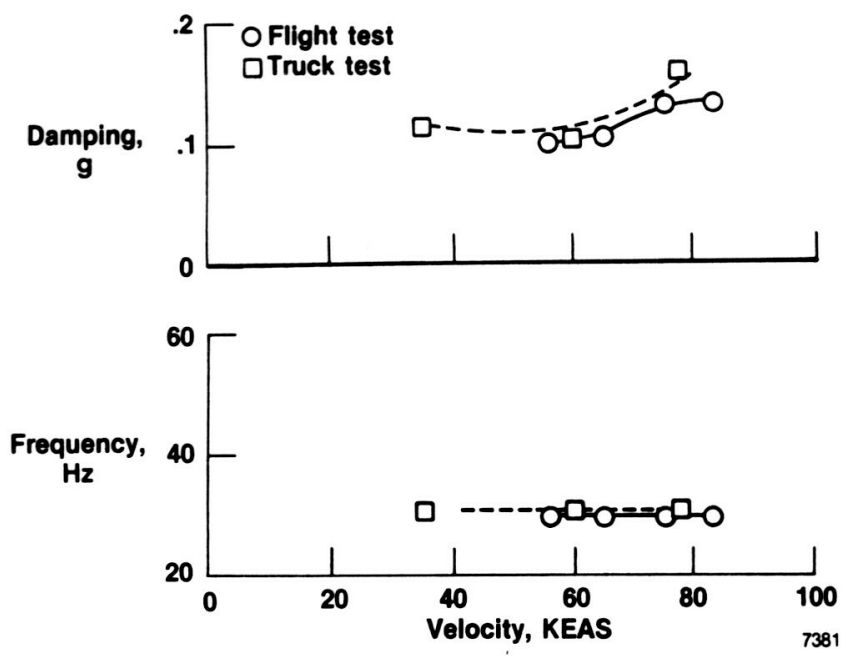

Fig. 20. Schweiser 1-36 symmetric horisontal stabilizer bending modal data.
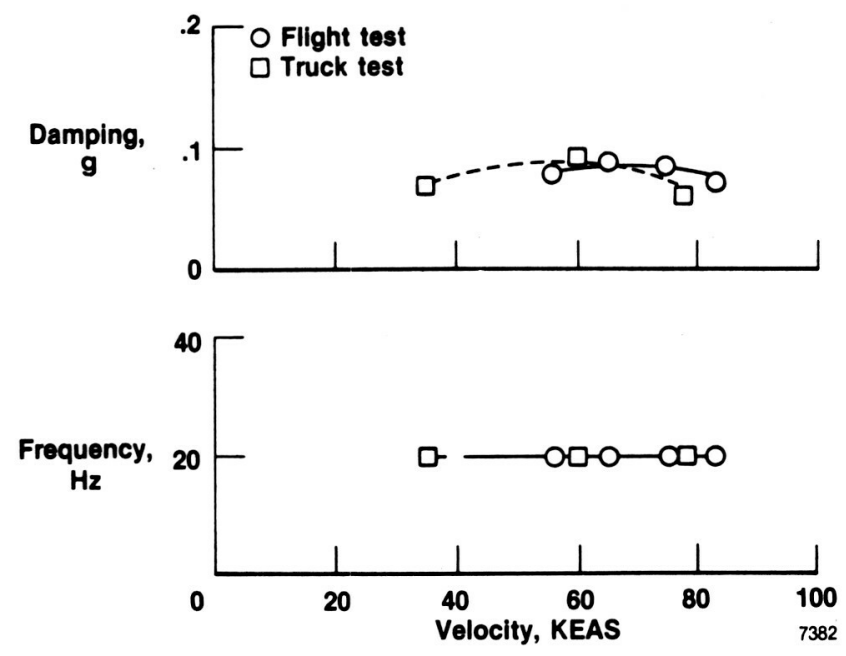

Fig. 21. Schweizer 1-36 vertical fin bending modal data.

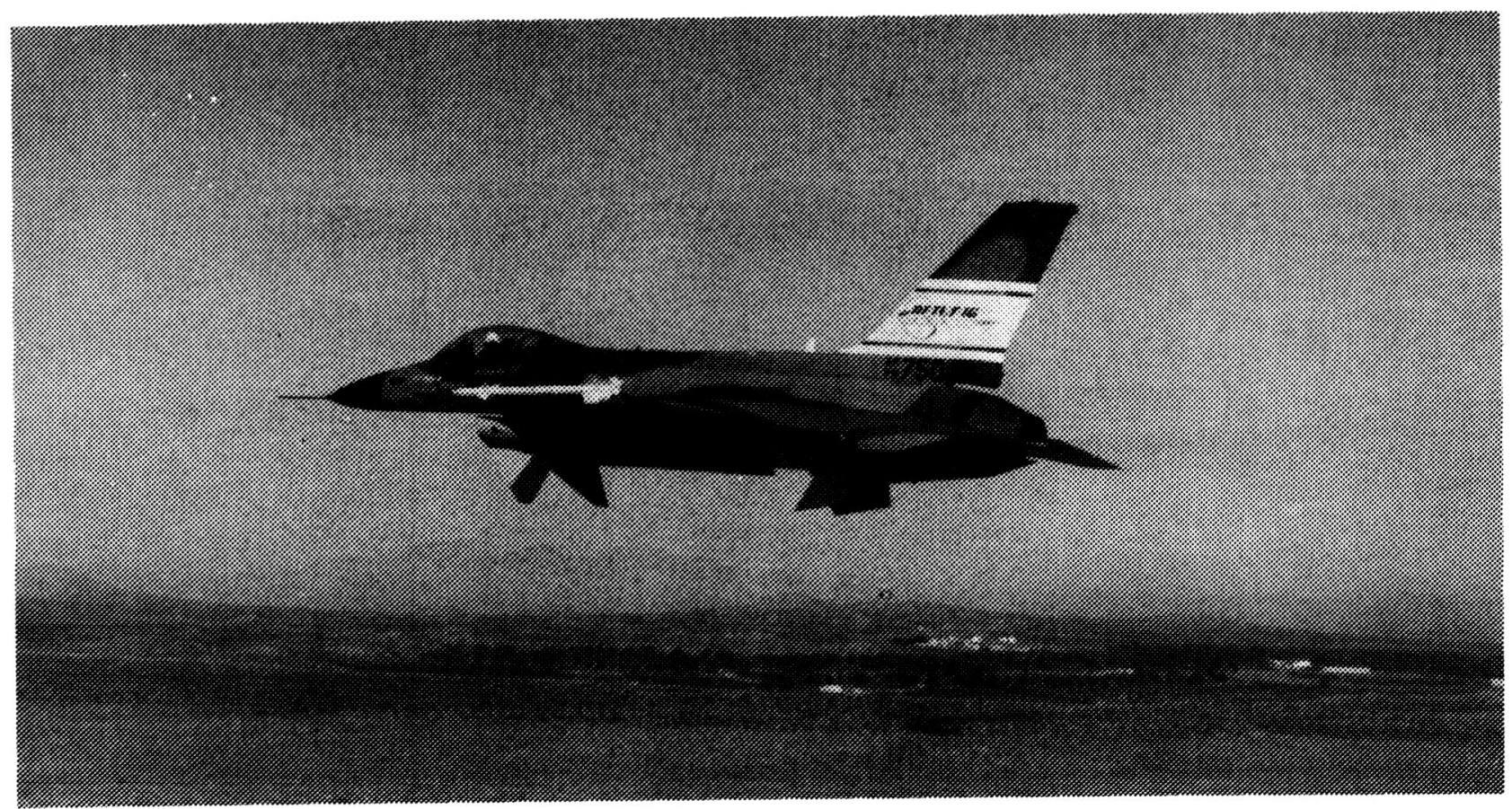

Fig. 22. AFTI/F-16 airplane.

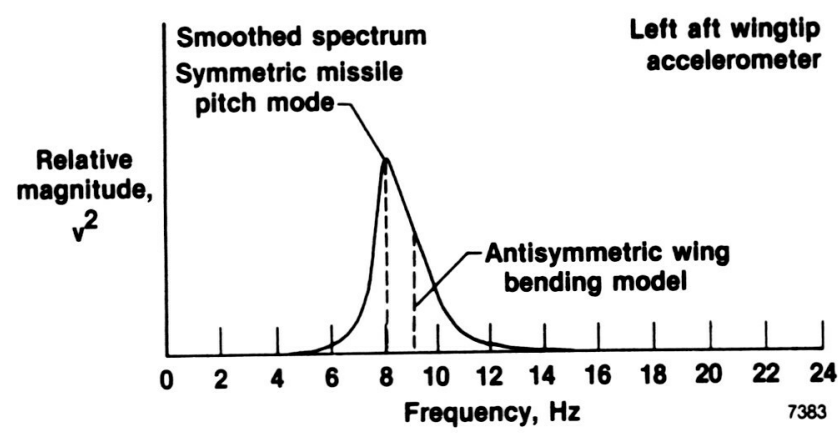

Fig. 23. Aft wingtip power spectrum showing modal smearing.
ORIGINAL PAGE IS OF POOR QUALITY

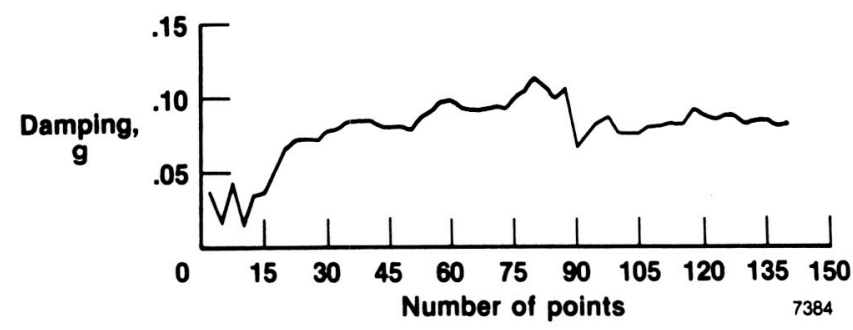

Fig. 24. Recursive filter algorithm damping estimate convergence. 


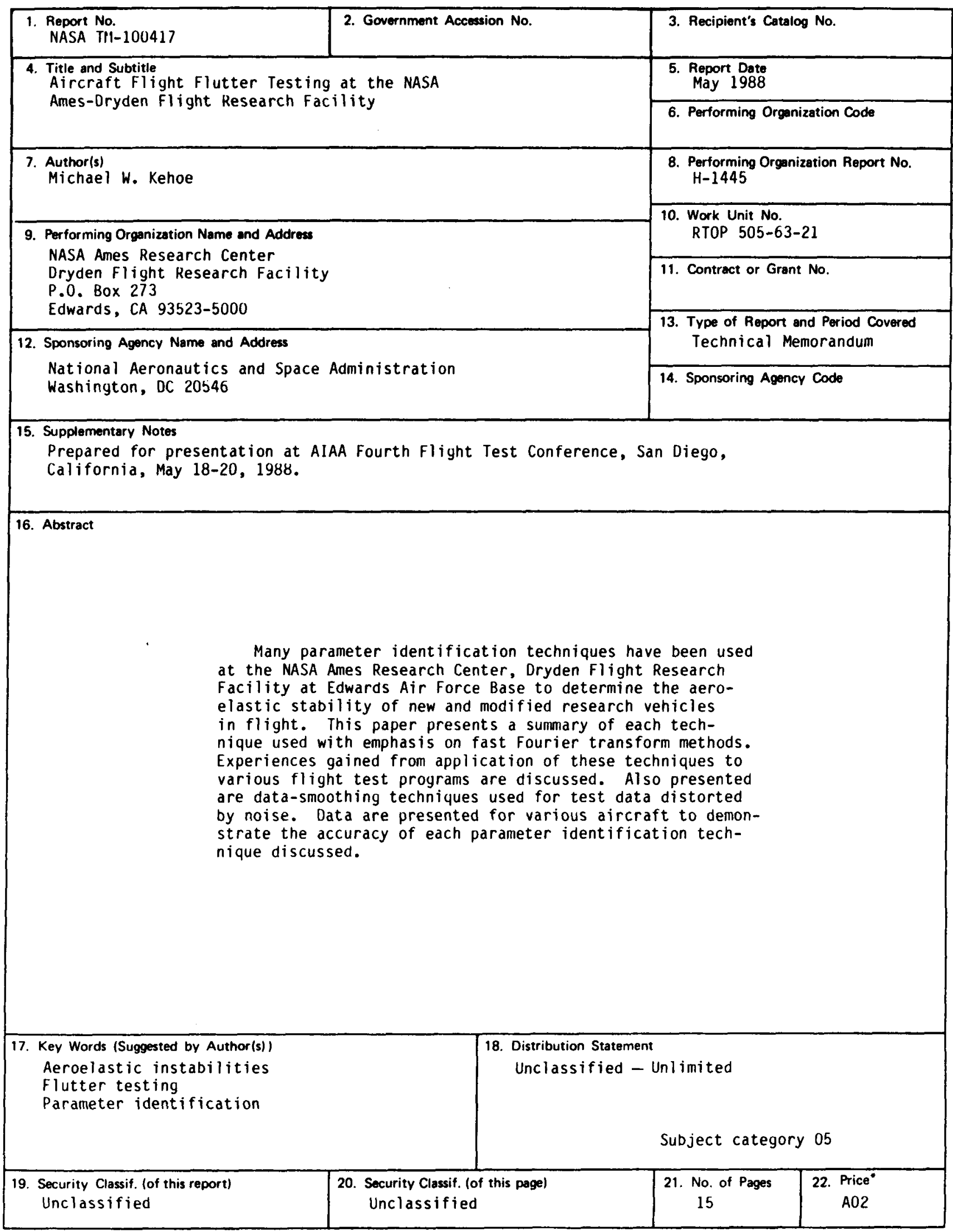

"For sale by the National Technical Information Service, Springfield, Virginia 22161. 